\title{
Bispos conservadores brasileiros no Concílio Vaticano II (1962-1965): D. Geraldo de Proença Sigaud e D. Antônio de Castro Mayer ${ }^{1}$
}

\author{
Brazilian conservative bishops at Vatican II
}

Rodrigo Coppe Caldeira*

\begin{abstract}
Resumo
Desde o século XIX o catolicismo foi assinalado por uma divisão interna advinda das demandas pastorais de como a Igreja Católica deveria se situar e responder aos novos desafios lançados pela modernidade. Uns entendiam que ela deveria dialogar com modernidade, abrindo-se àquelas perspectivas positivas do projeto moderno, outros negavam qualquer possibilidade de tal diálogo, vendo nos valores modernos apenas anticristianismo e perdição, defendendo o lançamento de anátemas aqueles que, possivelmente, se desviassem da ortodoxia. O Concílio Vaticano II (1962-1965) pode ser compreendido como um campo de lutas simbóliconormativas, no qual essas duas tendências colocaram-se frente a frente nos inúmeros debates. Este artigo tem como objetivo principal apresentar brevemente a atuação de dois bispos brasileiros conservadores no concílio: D. Antônio de Castro Mayer e D. Geraldo de Proença Sigaud (1962-1965). Para tanto, apresentaremos algumas das principais intervenções dos bispos na assembleia conciliar, chamando atenção para os temas em que travaram maior combate, como liberdade religiosa, liturgia e organização hierárquica da Igreja.
\end{abstract}

Palavras-chave: Bispos brasileiros. Conservadorismo católico. Concílio Vaticano II. Coetus Internationalis Patrum.

\begin{abstract}
Since the 19th century Catholicism has been marked by internal divisions arising from the pastoral demands of how the Catholic Church should position itself and deal with the new challenges launched by modern times. Some people understood that the Catholic Church was supposed to evolve with modern times and open itself to new perspectives related to the modern project. Others denied any possibility of dialogue with the modern times and believed that modern values would encourage scepticism and anti Christianity, defending also the excommunication of those who deviate from orthodoxy. The Second Vatican Council (1962-1965) can be understood as a symbolic-normative battle field, in which two divergent positions are in continuous confrontation. This article aims to briefly present the opinions of two Brazilian conservative Bishops in the Council: D. Antônio de Castro Mayer and D. Geraldo Proença Sigaud (1962-1965). For this purpose, the main points made by the Bishops at the Conciliar Assembly, will be outlined. Therefore, the focus of the article will be on the more controversial themes discussed at that time, such as religious freedom, liturgy and hierarchical Church organization.
\end{abstract}

Keywords: Brazilian bishops. Catholic conservatism. Second Vatican Council. Coetus Internationalis Patrum.

\footnotetext{
Artigo submetido em 18 de novembro de 2011 e aprovado em 26 de dezembro de 2011.

${ }^{1}$ Este artigo reflete parte de tese de doutorado defendida em novembro de 2009. O autor foi contemplado com bolsa do Conselho Nacional de Desenvolvimento Científico e Tecnológico (CNPq).

* Doutor em Ciência da Religião (UFJF), professor Adjunto da PUC Minas, departamento de Ciências da Religião. País de origem: Brasil. E-mail: rcoppe@ hotmail.com
} 


\section{Introdução}

Sem receio da afirmação peremptória, o Concílio Vaticano II (1962-1965) foi o maior evento religioso do século XX. Com a participação de milhares de bispos dos quatro cantos do planeta e os olhares de todo o mundo virados para Roma, o evento teve uma dimensão jamais vivida por um concílio ecumênico na história do cristianismo. Tendo sido o $21^{\circ}$ entre os concílios da Igreja Católica, o Vaticano II diferenciou-se também pela forma como foi realizado, de seus primeiros impulsos, com a convocação de João XXIII em janeiro de 1959, a sua tentativa de distensão com a modernidade e seus valores e à dinâmica que perpassou as discussões e os trabalhos de construção de seus documentos.

Uma das questões mais analisadas pelos historiadores e por outros analistas da história da Igreja Romana no século XX foram os impactos, seculares, do projeto de modernidade, que avançavam a passos largos no século passado sobre a instituição e como ela reagiu a eles, absorvendo alguns elementos desse projeto, recusando e anatematizando outros tantos. Interpretando a partir de uma perspectiva histórico-sociológica, é possível compreender o Vaticano II como um momento de inflexão de um movimento de divisão interna do catolicismo moderno: o chamado progressismo católico, ligado à visão de mundo marcadamente otimista em relação às promessas da modernidade, estendidas para o interior do orbe católica, e certo conservadorismo católico, negador de qualquer possibilidade de construção de pontes entre o catolicismo e os valores modernos, entendidos, grosso modo, como demoníaco e anticristão.

Dessa forma, o artigo apresentado objetiva demonstrar como dois bispos conservadores brasileiros - D. Antônio de Castro Mayer e D. Geraldo de Proença Sigaud, ligados diretamente a Plínio Corrêa de Oliveira e à Associação para a Defesa da Tradição, Família e Propriedade, a TFP - atuaram no concílio. Para tanto, as fontes utilizadas serão as Acta Synodalia ${ }^{3}$, as atas de intervenções de ambos os bispos, e algumas cartas pessoais, trazendo à tona elementos das principais disputas no interior da assembleia, exemplificadas com as palavras dos próprios bispos.

\footnotetext{
${ }^{3}$ As intervenções que serão apresentadas a seguir são traduções diretas das Actas Synodalia Sacrosancti Concilii Oecumenici Vaticani II (1962-1965, publicadas originalmente em latim. (CONCÍLIO VATICANO, 2, 1970).
} 


\section{Delineando a posição conservadora: do pré-concílio à preparação}

As divisões que marcariam a assembleia conciliar do século $\mathrm{XX}$ já estavam assentadas desde muito antes de sua realização, entre 1962 e 1965. De fato, as divisões em torno da questão crucial para a Igreja contemporânea de como ela deveria atuar - quer dizer, uma questão pastoral - diante dos novos tempos e seus desafios iniciou-se, sobretudo, no século XIX. Na verdade, pensando a partir da estrutura eclesiástica, nas pessoas de seus representantes, as respostas foram, sobretudo, de contenção e reação. Atitudes - assinaladamente conservadoras ${ }^{4}$ - que surgiram naturalmente como uma resposta aos ataques advindos de todos os lados. O nome do período em que a Igreja fechou-se progressivamente para o mundo moderno e seus valores ficou conhecido como ultramontanismo. Marcado pelos papados de Gregório XVI, Pio IX, Leão XIII e Pio X, esse período da história da Igreja assinalou-se por um olhar sempre desconfiado e anatematizante de toda e qualquer crítica a seus posicionamentos no que tange ao poder secular, e também no que tangia, especialmente no início do século XX, à questão teológica 5 .

De fato, as divisões modernas na Igreja de Roma apresentaram-se, sobretudo nesse período, momento em que as mudanças sociais, econômicas e culturais, advindas do projeto de modernidade e das transformações capitalistas, levavam-na a tomar posições claras em relações a elas. Duas posições foram se formando, então, a fim de oferecer uma resposta pastoral aos problemas do período: uma, que desde o século XIX se firmava cada vez mais, aberta, de certa maneira, às perspectivas modernas, constituíram as bases do que hoje os estudiosos chamam catolicismo progressista, e, por outro lado, aqueles que, vendo na modernidade perdição e palco privilegiado do demônio, se entrincheiraram contra qualquer aproximação daqueles valores, os conservadores católicos.

Lendo a história da Igreja do final do século XIX e da primeira metade do século $\mathrm{XX}$, nota-se que a ideia de um concílio tinha sido aventada algumas vezes, inclusive a necessidade de se colocar termo no próprio Concílio Vaticano, que terminou de forma

\footnotetext{
${ }^{4}$ Sobre o conceito de conservadorismo, ver Foracchi (1982).

${ }^{5}$ Cf. os documentos vaticanos: Mirari vos (DzH 2730-2732), Qui pluribus (DzH 2775-2786), Quanta cura (DzH 2890-2896), Syllabus Errorum Modernorum (DzH 2901-2980), Humanum genus (DzH 3156-3158), Lamentabili (DzH 3401-3466), Pascendi dominici gregis (DzH 3475-3500), entre outros.
}

Horizonte, Belo Horizonte, v. 9, n. 24, p. 1010-1029, dez. 2011 - ISSN: 2175-5841 
abrupta devido à chegada das tropas de unificação a Roma. João XXIII, ao convocar um novo concílio, de espírito notadamente diferente dos anteriores - era um concílio que visava a um dialogo com o mundo e não a condenação de suas ideias - dava margem para que os inúmeros movimentos católicos de aproximação com os valores modernos pudessem se fazer presentes pelas vozes de inúmeros bispos mais sensíveis, e mesmo apoiadores, às suas demandas.

Desde a preparação do concílio, entre 1959 e 1962, é possível observar a organização das forças que iriam se chocar na assembleia conciliar, e os bispos conservadores, como Geraldo de Proença Sigaud ${ }^{6}$, de Diamantina (Minas Gerais), e Antônio de Castro Mayer ${ }^{7}$, de Campos dos Goytacazes (Rio de Janeiro), já deixam às claras as posições que vão tomar nas futuras discussões, quando respondem a "consulta Tardini"”.

Segundo Baraúna, o maior objetivo do concílio para os dois prelados deveria ser:

\begin{abstract}
a) denunciar e condenar os erros e desatinos do mundo moderno, que vêm penetrando profundamente na Igreja, e muito particularmente entre os seminaristas, padres, os teólogos e boa parte até dos bispos. Estes erros são basicamente o naturalismo, o materialismo, o modernismo, o comunismo ateu, a permissividade nas doutrinas e nos costumes;

b) repropor à Igreja universal, como modelo supremo, a restauração plena da "cristandade" ("civitas christiana"), da soberania de Deus e de sua Igreja sobre o mundo;
\end{abstract}

\footnotetext{
${ }^{6}$ Geraldo Proença Sigaud nasceu em Belo Horizonte em 16 de setembro de 1909 e foi ordenado em 1932. Foi sagrado bispo para a cidade de Jacarezinho (PR) em 1947, na qual cumpriu seu exercício até 1961, ano em que se tornou Arcebispo Metropolitano de Diamantina (MG). Escreveu a Pastoral sobre a seita comunista e um pequeno livro intitulado Catecismo anticomunista.

${ }^{7}$ Antonio de Castro Mayer nasceu em Campinas em 20 de junho de 1906. Foi ordenado sacerdote em Roma, em 1927.Como bispo, foi coadjutor com direito à sucessão em Campos (RJ), em 1948, onde foi bispo diocesano entre 1949 e 1981. Escreveu as seguintes obras: Reforma agrária: questão de consciência (1964), em colaboração com Geraldo Proença Sigaud, Dr. Plínio Corrêa de Oliveira e Dr. Luiz Mendonça de Freitas, Por um cristianismo autêntico, coletânea de Pastorais; E eles o crucificaram, Sermões da Sexta-feira Santa, Cursilhos da Cristandade (1972); Pelo casamento indissolúvel (1975) A Realeza de Nosso Senhor Jesus Cristo (1977); A mediação universal de Maria Santíssima (1979); coluna semanal em O Monitor Campista sob o pseudônimo de DAC. Sobre mons. Lefebvre, ver Chalet (1977).

${ }^{8}$ Segundo Baraúna (1993), pode-se encontrar entre os bispos brasileiros três correntes de respostas: 1) Uma minoria ultraconservadora que é marcada pelo tom condenatório da modernidade e seus valores, especialmente contra o comunismo e associações como a Maçonaria, o Rotary Club, o Lions Club; 2) Uma minoria que dá ênfase à "Igreja ad extra" e não à "Igreja ad intra"; que se posiciona em favor do diálogo à luta contra determinadas ideias; marcada como "precursora e profética, que revela claramente a consciência de que chegou o momento de a Igreja relativizar uma pequena tradição (a pós-tridentina) para reatar com a grande Tradição"; 3) Uma maioria constituída por conservadores e moderados. Esses bispos apontam para a necessidade de reformas na liturgia, na disciplina eclesiástica e no Direito Canônico, porém, respeitando e se comprometendo com a chamada "Tradição da Igreja” (BARAÚNA, 1993, p. 151).
} 
c) mobilizar a Igreja universal, sob liderança do papa, para a grande cruzada "contrarrevolucionária" da restauração da "cristandade". (BARAÚNA, 1993, p. $152)$.

Sigaud, em sua resposta à consulta ${ }^{9}$, deixa claro quais são os seus inimigos, tidos como também inimigos da Igreja:

Estudando a vida da Igreja no Brasil, no mundo, observo nela um enfraquecimento grande interno, uma profunda penetração dos erros e do espírito do mundo. Ao lado disto vejo um silêncio impressionante dos Bispos, uma colaboração positiva de muitos membros do Clero no trabalho da Revolução. Vejo mesmo em muitas partes como a Hierarquia persegue os que falam e agem contra a Revolução. Em lugar de lutar abertamente contra a Revolução, muitos membros da Hierarquia impedem que os bons sacerdotes, leigos lutem. São promovidos ao episcopado Bispos revolucionários, e estes têm toda a liberdade de ação (ARQUIVO DA BIBLIOTECA DOS REDENTORISTAS DE SÃO PAULO, 1960).

Ecoando as falas dos contrarrevolucionários franceses do século XIX, Sigaud acredita, como Plínio Corrêa de Oliveira, o fundador da TFP e seu amigo próximo, que o maior inimigo da Igreja tem nome: a Revolução. Entre seus agentes, o prelado aponta a maçonaria e o “judaísmo internacional”. Num dos trechos afirma que os

[...] olhares do Concílio de todo a Igreja devem se dirigir vivamente para esta Seita, a Franco-Maçonaria. As encíclicas dos Papas sobre esta seita são atualíssimas [...] é necessário ensinar aos católicos que a Maçonaria é a grande inimiga da Igreja, sua inimiga de morte, e que ela é uma organização mundial poderosíssima, que dirige e fomenta a luta mundial e definitiva contra a Igreja (ARQUIVO DA BIBLIOTECA DOS REDENTORISTAS DE SÃO PAULO, 1960).

O bispo vê um íntimo relacionamento entre judaísmo, comunismo e maçonaria:

Os líderes desse judaísmo desde séculos conspiram contra o Nome Católico, e de maneira metódica e com ódio mortal preparam a destruição da Ordem Católica e constroem a Ordem do Império judaico mundial. Para isso servem a Maçonaria e o Comunismo. O dinheiro, os meios de informação e a política mundial em grande parte estão nas mãos dos Judeus. Embora sejam os maiores capitalistas, e portanto deveriam ser os maiores adversários da Rússia e do Comunismo, não têm medo dele; pelo contrário, ajudam-no a conquistar a vitória. Os traidores dos segredos atômicos dos Estados Unidos da América foram Fuchs - Golds Gringlass - Rosenberg: todos judeus. Os fundadores do Comunismo são judeus, (e são também eles) os pregadores, organizadores e "financiadores". Trata-se do

\footnotetext{
${ }^{9}$ O rascunho da resposta de Sigaud foi encontrado no Fundo arquivístico de Sigaud, Fundo Vaticano II de São Paulo. Interessante notar que a resposta enviada a Roma é mais completa.
} 
interesse deles. Esta é a realidade. Deve-se então odiá-los? Não! Mas há que opor vigilância, clareza, luta sistemática e metódica à luta sistemática e metódica desde "Inimigo do Homem", cuja arma secreta é "o fermento dos fariseus que é a hipocrisia” (ARQUIVO DA BIBLIOTECA DOS REDENTORISTAS DE SÃO PAULO, 1960).

Antonio de Castro Mayer, por seu turno, também não se esquiva de pedir condenações ao concílio. Contudo, volta-se para questões mais filosóficas, como, por exemplo, as relações do cristianismo e o socialismo (BEOZZO, 2005). Dessa forma, o socialismo é o principal ponto no qual Mayer pede suas condenações:

\begin{abstract}
Parece-me oportuno dissipar qualquer confusão, declarando, por exemplo, que a ordem da sociedade sonhada pelos socialistas, baseada somente no amor e no progresso científico, é contra a atual disposição da Divina Providência, porque a desigualdade entre os seres humanos não constitui, de modo algum, um mal, mas manifesta do melhor modo a perfeição de Deus na presente ordem hierárquica das coisas e dos seres humanos; tanto mais que, na absoluta igualdade de todos os seres humanos, certas virtudes cristãs, das mais necessárias para a salvação, como a humildade, a obediência, a misericórdia etc., tornam-se quase impossíveis. O peso que padecem os seres humanos por conta da desigualdade, seja considerado como pena do pecado original e como meio para que pratiquem as virtudes (BEOZZO, 2005, p. 111-112).
\end{abstract}

Bem, poderíamos multiplicar as falas das respostas dos dois bispos à consulta, porém, agora, interessa-nos apontar brevemente para os momentos mais centrais da atuação de ambos na assembleia conciliar. Sigaud fez 10 intervenções no concílio, ao passo que Mayer, por seu turno, realizou 28 , escritas e públicas, na assembleia conciliar ${ }^{10}$. Não é possível aqui apresentar a estrutura do Coetus Internationalis Patrum, o grupo que tentou organizar a minoria conciliar e que teve participação marcante de Mayer e Sigaud, a fim de combater a avalanche liberal que sobrevinha no horizonte.

\title{
2 Sigaud e Mayer: combates pela tradição contra a "dissolução moderna" dentro do concílio
}

Em três momentos específicos chama atenção a atuação de Mayer e Sigaud no concílio: nas discussões sobre a liberdade religiosa e no esforço de tirar do concílio uma

\footnotetext{
${ }^{10}$ Cf Beozzo (2005).
} 
condenação explícita do comunismo e no empenho pela consagração do mundo, especialmente a Rússia, ao "Coração Imaculado de Maria".

Como se sabe, a gênese do documento sobre a liberdade religiosa encontra nas discussões sobre o ecumenismo. Em vista das discussões do primeiro capítulo do esquema "De oecumenismo", Castro Mayer afirma em uma de suas intervenções, demonstrando o apreço pela centralidade da figura do papa:

O esquema, nesse capítulo, não diferencia a Igreja Católica Romana das outras comunidades cristãs. Não diz claramente e com termos unívocos que somente a Igreja Católica Romana é a verdadeira Igreja que está sob a autoridade do Sumo Pontífice e sua suprema autoridade que, por sua vez, a exerce sobre todos os fiéis e bispos e também com infalibilidade (CONCÍLIO VATICANO 2, 1970, v.2, pt. 2, p. 109; AS II/2, p. 109).

Mais à frente, assevera contra possíveis eufemismos eclesiológicos no corpo do texto em debate:

\begin{abstract}
A palavra "Igreja" é usada tanto para a verdadeira Igreja de Cristo como para as outras comunidades cristãs. Porém, a verdadeira Igreja de Cristo difere das outras comunidades que se decoram com o nome de Cristo. A verdadeira Igreja de Cristo é uma sociedade sobrenatural, cuja alma, o Espírito Santo, une intimamente entre si, todos os membros [...]; seja reservada a palavra "Igreja" para a verdadeira Igreja de Cristo; mas como também é atribuída a outras comunidades cristãs, seja acrescentada uma exposição na qual apareça claramente que tais comunidades só são chamadas de "Igrejas" por certa analogia (CONCÍLIO VATICANO 2, 1970, v.2, pt. 2, p. 111-112; AS II/2, p. 111-112).
\end{abstract}

Porém, os momentos mais drásticos em torno do esquema não foram aqueles que tocavam a questão do ecumenismo, mas, sim, quando se desmembra do documento "De oecumenismo" e, entre 1963 e 1964, passa-se a discutir o esquema "De libertate". De fato, a discussão desse esquema levou Sigaud e Mayer, juntamente àqueles que iriam fundar o Coetus Internationalis Patrum em outubro de 1964, a questionar profundamente o esquema como apresentado, já que nele observava-se uma guinada na compreensão dos documentos pontifícios centrais na compreensão das relações entre Igreja e mundo de ambos os bispos, o Syllabus Errorum Modernorum.

Central para o Concílio e o contexto histórico, com repercussões também na "semana negra", foram as discussões em torno da liberdade religiosa. No primeiro esquema sobre a Igreja, rejeitado pelos padres na primeira sessão, havia um capítulo que tratava sobre as suas relações com o Estado (WILTGEN, 2007). Tal tema era central para a vida da 
Igreja desde a perda dos Estados Papais no século XIX, além de também estar estritamente vinculado ao tema das missões em países onde os cristãos sofriam duras perseguições. Dessa forma, alguns padres viam a necessidade de o Concílio despender algum tempo com o assunto, em 23 de setembro. O texto, que havia sido apresentado como capítulo do esquema ecumênico, e defendido fortemente por Bea, foi revisto, refeito e a apresentado, então, por De Smedt, como declaração separada. As divisões sobre o texto haviam vindo à tona durante o segundo período, quando o esquema De Oecumenismo havia sido debatido em seus aspectos gerais. Três sensibilidades haviam se delineado no momento: a que considerava oportuno o capítulo (cardeais Ritter e Meyer e os bispos Jelmini e Méndez Arceo), os que viam o texto como bom, mas que não deveria entrar no esquema (Florit, Léger, Hervás y Benet) e aqueles que desejavam adiar a discussão ou mesmo rejeitavam absolutamente o texto (Patriarca Tappouni e o cardeal Bacci, ambos próximos ao Coetus) (KLOPPENBURG, 1963).

Em uma Animadversiones Scripta, Sigaud deixa transparecer claramente qual era o sentimento dos antimodernos naquela sessão sobre os textos a serem discutidos. Falando sobre a vigília da terceira sessão e os estudos dos esquemas, Sigaud, que também escreve em nome de outros bispos, afirma: "Diante de algumas destas proposições, devemos confessar nossa emoção e nossa viva ansiedade" (CONCÍLIO VATICANO 2, 1970, v.3, pt. 1, p. 678; AS III/1, p. 678). O temor do arcebispo é em relação às possíveis falsas interpretações das proposições, para ele, novas e contrárias à tradição da Igreja, que poderiam surgir no pós-Concílio:

\begin{abstract}
O equívoco tem por resultado expor ao perigo de interpretações falsas e permitir desenvolvimentos que não são seguros no pensamento dos Padres Conciliares. Algumas "formulações" são novas e até completamente inesperadas. A nosso ver, elas chegam ao ponto de parecerem não conservar "o mesmo sentido e o mesmo alcance" das que a Igreja empregava até aqui. Para nós, que quisemos nos mostrar dóceis à Encíclica Humani Generis, nossa perplexidade é grande (CONCÍLIO VATICANO 2, 1970, v. 3, pt. 1, p. 678; AS III/1, p. 678)).
\end{abstract}

Segundo Sigaud, alguns esquemas, particularmente De Oecumenisme e De libertate religiosa, colocam-se contrariamente em seus termos contra tudo o que foi ensinado pelo Magistério Ordinário e Extraordinário da Igreja: 
[...] são assim [...] expressos em termos e em um sentido que, se não contradizem sempre, pelo menos opõem-se formalmente, tanto aos ensinamentos do Magistério Ordinário quanto às declarações do Magistério extraordinário vigentes na Igreja há mais de um século. Nós não reconhecemos mais aí a teologia católica nem a sã filosofia que deve, pela razão, esclarecer os caminhos (CONCÍLIO VATICANO 2, 1970, v.3, pt. 1, p. 679; AS III/1, p. 679).

Termina o documento pedindo que o papa tome providências e recorde na abertura da terceira sessão que

[...] a doutrina da Igreja deve ser expressa sem ambiguidade, que é respeitando esta exigência que ela levará as luzes novas necessárias ao nosso tempo, sem nada sacrificar dos valores que ela já dispensou ao mundo, e sem se expor a servir de pretexto a um ressurgimento de erros sem cessar reprovados há mais de um século (CONCÍLIO VATICANO 2, 1970, v. 3, pt. 1, p. 679; AS III/1, p. 679).

Mayer, por seu turno, chama atenção é para a defesa de que as relações entre a religião e a sociedade devem derivar da lei natural e da lei positiva de Deus. É lei de Deus, afirma que todos aceitem a verdadeira religião, dessa forma, o Estado não pode favorecer as falsas religiões: “As mútuas relações das pessoas que vivem na sociedade devem apoiar-se na lei natural e na lei positiva de Deus. É a lei de Deus que todos abracem a verdadeira fé e entrem para a verdadeira Igreja; e para que isso seja obtido de todos, Deus lhes vêm em auxílio com sua graça, e assim, ninguém é condenado sem culpa própria" (CONCÍLIO VATICANO 2, 1970, v. 3, pt. 2, p. 485; AS III/2, p. 485).

Não obstante as poucas intervenções de Mayer e Sigaud sobre os temas, as questões referentes à liberdade religiosa e às relações dos cristãos com os judeus eram consideradas de crucial importância para os antimodernos. Como já visto anteriormente, os judeus eram tidos pelos antimodernos como um dos grandes responsáveis pelas ideologias modernas, principalmente o comunismo ateu, que perseguia e assassinava os cristãos por toda a Europa oriental e na URSS. Dessa forma, a posição tomada por eles era de estrita negação a qualquer diálogo com os judeus e seus órgãos máximos.

Mayer, em outra de suas Animadversiones Scriptae defende incisivamente que se mantenha a tradição da culpabilidade dos judeus da morte de Jesus. Para isso, recorre às fontes bíblicas a fim de corroborar sua posição: "Os israelitas de hoje são sucessores daqueles a respeito dos quais São Pedro afirma terem entregado Jesus à morte, e São Paulo, terem desconhecido a justiça de Deus e conservado o coração endurecido (At 3, 13; 5, 20; 
Rom 10, 3; 11, 7)" (CONCÍlIO VATICANO 2, 1970, v.3, pt. 3, p. 161; AS III/3, p. 161).

Além disso, sugere cautela em relação ao diálogo com os judeus, comportamento que marcou toda a história da Igreja:

Daí também se conclui que o diálogo com os judeus pode ser introduzido, mas com grande cautela como é de praxe ou pelo menos sempre foi na Igreja. Por isso, o Concílio não deve abandonar tal costume a não ser por causas graves que deveriam ser explicadas aos fiéis (CONCÍLIO VATICANO 2, 1970, v.3, pt. 3, p. 161; AS III/3, p. 161).

Refletindo sobre a situação dos não cristãos em geral, Mayer afirma:

Os não cristãos, segundo o princípio dogmático a respeito do desígnio de Deus da salvação universal, tiveram e têm a graça suficiente para abraçar a verdadeira fé e incorporar-se à Igreja [...]. Conforme esse modo de agir, outra verdade poderia licitamente ser posta em dúvida, a saber, aquela da necessidade da Igreja católica visível como meio ordinário de salvação para todos os homens (CONCÍLIO VATICANO 2, 1970, v.3, pt. 3, p. 162; AS III/3, p. 162).

Sigaud faz uma intervenção escrita de nove páginas. Subscritada também por Mayer, o arcebispo de Diamantina faz uma longa digressão, abusando das citações de documentos papais dos séculos XIX e XX, visa a defender a tese de tolerância religiosa, mas não de liberdade religiosa, que seria contrário ao próprio Magistério eclesiástico anterior. De acordo com o arcebispo, "o esquema parece não levar suficientemente em conta princípios inabaláveis, e algumas noções são usadas sem que sejam consideradas as deformações pelas quais passaram por influxo do liberalismo" (CONCÍLIO VATICANO 2, 1970, v. 3, pt. 3, p. 648; AS III/3, p. 648). Sigaud afirma que:

A verdade e o bem são próprios da natureza humana. Cabe à razão ponderar e dispor. O homem, portanto, tem o direito de aderir à verdade e de operar o bem, porque, de outro modo, isto é, se ele for privado da faculdade de aderir à verdade e de operar o bem, sua natureza ficaria frustrada, o que seria contrário ao desígnio do Criador [...] O homem deve livremente determinar-se na escolha do seu fim último (CONCÍLIO VATICANO 2, 1970, v. 3, pt. 3, p. 649; AS III/3, p. 649). 
Além disso, afirma que:

\begin{abstract}
Esta liberdade interna é um direito para o homem e ninguém pode ser coagido em interesse desta ou daquela ideologia. E não somente isso. A liberdade de adesão ao erro ou ao mal ulterior não é um direito natural. De si, portanto, na convivência social, pode acontecer a manifestação externa de consenso ao erro e por isso deve ser impedida: primeiro, porque o erro é contra a natureza humana o que é racional - e segundo, porque a manifestação do erro, especialmente religiosa, prejudica aos outros, já que pode apresentar-se a eles como um escândalo (CONCÍLIO VATICANO 2, 1970, v. 3, pt. 3, p. 649; AS III/3, p. 649).
\end{abstract}

O tema do comunismo, muito próximo da questão da liberdade religiosa e da questão mariana, já que os bispos pediam uma consagração do mundo e, especialmente da Rússia - onde as perseguições aos cristãos eram contínuas -, ao Coração Imaculado de Maria foi um daqueles que mais movimentaram Sigaud e Mayer nos bastidores do concílio.

Sigaud, um aficcionado pela temática, já havia publicado, inclusive, um Catecismo anticomunista. Antes de sua chegada ao concílio. Na verdade, desde a década de 1930, Sigaud, muito próximo do grupo do jornal $O$ Legionário, de Plínio Corrêa de Oliveira, já se imbuía de uma tradição fortemente anticomunista, o que aparecerá no concílio ${ }^{11}$. Entre os padres antimodernos corria a ideia de que a presença da maçonaria e do comunismo visavam a impor ao concílio suas supostas teses heréticas e contrárias à tradição.

No início da intersessão de 1963, Sigaud passou por Fátima, Portugal, e lá teve contato com o bispo de Leiria João Pereira Venâncio, que pediu ao arcebispo de Diamantina que se incumbisse de convidar os bispos brasileiros a assinar a petição que pedia a consagração do mundo a Nossa Senhora. A fim de corroborar sua atuação na empreitada, Sigaud solicita a Venâncio uma carta pedindo-o formalmente a realização de sua iniciativa, aludindo ao encontro que tiveram em Fátima e que a carta contivesse, também, uma sugestão do bispo português de que fosse formada uma comissão de arcebispos e bispos residenciais brasileiros distinta da Conferência Nacional dos Bispos do Brasil (ARQUIVO DA BIBLIOTECA DOS REDENTORISTAS DE SÃO PAULO, 1963).

\footnotetext{
${ }^{11}$ Várias Cartas Pastorais, de inúmeros bispos, foram escritas nesse período com o intuito de esclarecer os católicos do "perigo" comunista: O Communismo Russo e a Civilização Christã, escrita por D. João Becker em 1930; Carta Pastoral e Mandamento do Episcopado Brasileiro sobre o Comunismo Ateu, documento coletivo dos bispos brasileiros, publicada em 1937; Sobre o Comunismo, do bispo Coadjutor de São Carlos, D. Gastão Liberal Pinto, de 1937; Carta Pastoral contra o comunismo, escrita pelos bispos da Bahia em 1937 e Carta Pastoral O Comunismo e o Momento Nacional, dos bispos gaúchos, escrita em 1945 (MOTTA, 2002).
} 
Parece, dessa forma, que Sigaud buscava afastar a CNBB de seu projeto, visto que ela, em sua grande maioria, apoiava a Aliança (BEOZZO, 2005).

Contudo, Venâncio, em carta de março de 1963, não atende totalmente aos pedidos de Sigaud, dizendo que sua interferência aberta no assunto poderia atrapalhar o andamento do projeto. Não obstante, pedindo sigilo sobre o assunto, oferece ao arcebispo total ajuda financeira na empreitada: "quanto me seria grato que todas as despesas a efetuar com esta diligência, que confio ao Coração Imaculado de Maria, corressem todas pelo Santuário, digo, por conta do Santuário de Fátima" (ARQUIVO DA BIBLIOTECA DOS REDENTORISTAS DE SÃO PAULO, [1963?]).

Em 12 de julho de 1963, Sigaud enviou aos bispos do Concílio a carta em nome de alguns bispos brasileiros, pedindo a assinatura da petição e o anexo no qual o bispo subscreveria e que seria entregue ao papa em fevereiro de 1964. Contudo, devido ao atraso dos correios e à partida dos bispos para a segunda sessão do Concílio, as cartas não chegam aos destinatários. Sigaud luta contra o tempo e as reenvia juntamente à petição em 12 de novembro (ARQUIVO DA CÚRIA METROPOLITANA DE DIAMANTINA, [1963?]).

Como dito acima, a questão mariana, nos termos em que Sigaud e vários antimodernos desejavam que prevalecessem no Concílio, estava ligada intimamente com outro mote que perpassava a cabeça do arcebispo de Diamantina há décadas: o comunismo.

Os dois temas ligavam-se devido às supostas aparições de Nossa Senhora em Fátima, em 1917. A Virgem, em sua aparição, teria confiado três mensagens a três pastorzinhos: na primeira delas a Virgem teria mostrado o inferno às crianças, e lhes explicou que a Primeira Grande Guerra Mundial (1914-1917) teria sido provocada pelos pecados dos homens; o segundo afirmava que a Primeira Guerra acabaria, alertando para o fato de que, se os homens não emendassem de seus pecados, uma guerra pior ocorreria (Segunda Grande Guerra Mundial) além de prever a expansão do comunismo, como castigo divino, caso os homens não se reparassem. Mesmo já em sua primeira carta pastoral à população de Jacarezinho se vislumbrava o papel que a Virgem de Fátima desempenhava em sua percepção de mundo (SIGAUD, 1947).

Dessa forma, a luta do arcebispo de Diamantina pela consagração do mundo, e especialmente da Rússia, ligava-se à sua luta posterior no Concílio, especificamente na 
terceira e quarta sessões, de inserir no texto do esquema "A Igreja no mundo de hoje" uma condenação explícita do comunismo.

Em uma de suas intervenções, afirmava Sigaud:

Com certeza a Beatíssima Virgem, Mãe da Igreja, maternalmente receberá essa Consagração que, assim esperamos, será de algum modo o coroamento do próprio Concílio Ecumênico Vaticano II, e a aurora da verdadeira paz e da liberdade da Igreja, e trazendo aos nossos padres a preservação do tirânico comunismo, e às nações que gemem sob o jugo dos comunistas, a libertação (ARQUIVO DA BIBLIOTECA DOS REDENTORISTAS DE SÃO PAULO, 1964).

Como se sabe, a teoria marxista foi condenada inúmeras vezes pelo magistério ordinário da Igreja, o que fornecia aos antimodernos elementos de uma defesa também de sua condenação formal pelo Concílio. Na verdade, esse pedido já tinha sido expresso por muitos vota na fase antepreparatória, como demonstra Turbanti (1997), inclusive o vota próprio Sigaud. A gravidade da questão era clara. Sua discussão entrava no esquema sobre a Igreja no mundo contemporâneo e foi um dos maiores cavalos de batalha do Coetus, já que seus integrantes eram marcados por extrema sensibilidade anticomunista. Uma primeira petição, assinada por 200 padres, encabeçada pelo Coetus, e entregue ao cardeal Cicognani em dezembro de 1963 e que pedia um esquema especial que condenasse a doutrina marxista, havia ficado sem resposta. Contudo, a questão do ateísmo toma corpo entre os padres conciliares que solicitam, como Suenens, em outubro de 1964, que o fenômeno moderno não teria sido estudado em profundidade a fim de esclarecer os seus motivos. Em 14 de setembro, dia da abertura da quarta sessão, os padres tinham em mãos o esquema sobre a Igreja no mundo moderno (TURBANTI, 2000). Nele encontrava-se uma seção sobre o ateísmo. Contudo, não havia uma referência explícita ao comunismo. Tal fato levou 25 bispos a distribuírem uma carta, datada de 29 de setembro de 1965, enumerando as razões pelas quais o comunismo deveria ser abordado pelos padres conciliares ${ }^{12}$.

\footnotetext{
${ }^{12}$ Em seus Appunti do Concílio, Sigaud anota o seguinte: "Dia 9.X. 12 horas. Mons. Lefebvre e Mons Sigaud entregaram as $420(+30)$ Petições sobre o comunismo Schema XIII" (ARQUIVO DA CÚRIA METROPOLITANA DE DIAMANTINA, 1965). Wiltgen repete a informação em um comunicado de 17 de novembro de 1965: "In view of remarks made in the press, I have been asked by Archbishop Gerald Sigaud to state that it is not true that the written Council Intervention on Communism, containing 450 signatures of Council Fathers, was submitted to the Council Secretariat beyond the established time limit. Archbishop Sigaud told me over the phone this morning that he personally, together Archbishop Marcel Lefebvre, took the document with the signatures to the Office of Archbishop Pericle Felici, Secretary General of the Council, and presented it to the Archbishop's secretary on Saturday, October 9, at 12 noon” (ARQUIVO DA CÚRIA METROPOLITANA DE DIAMANTINA, 1965).
} 
Junto a ela estava anexada uma petição com 450 assinaturas $^{13}$.

A carta, escrita por Carli, foi distribuída por Lefebvre e Sigaud, "cujos nomes não figuravam entre as 25 assinaturas, por causa do grande antagonismo de que eles eram alvo" (WILTGEN, 2007, p. 276). O texto da carta era o seguinte:

Exmo. e Revmo. Senhor, os Padres Conciliares abaixo assinados saúdam-no muito respeitosamente no Senhor, e se permitem expor-lhe ISTO que segue: durante a discussão do Esquema da Igreja no mundo moderno, muitos Padres notaram que o Esquema não parte suficientemente da questão do Comunismo, muito pastoral hoje. As razões que eles invocam encontram-se em uma folha anexa. Pensamos que, certamente, após a leitura delas, V.R. as aprovará e assinará, como já fizeram 450 Padres do Concílio sobre os 800 que até o presente foram solicitados. Persuadidos de que, fazendo-lhe este pedido, estamos praticando uma obra eminentemente pastoral, nós lhe pedimos, Excelência, aceitar a expressão de nossos sentimentos, atenciosamente em N.S. (ISTITUTO PER LE SCIENZE RELIGIOSE DI BOLOGNA. 1965).

Nos arquivos de Sigaud em Diamantina encontra-se um documento justificando a necessidade de uma condenação ao comunismo que parece ser aquele que foi entregue à secretaria do Concílio com as assinaturas dos padres conciliares:

À SECRETARIA GERAL do CONCÍLIO VATICANO II. Os abaixo assinados Padres Conciliares pedem reverentemente que, após o § do Esquema "A Igreja no mundo de hoje", que trata do ateísmo, se acrescente um novo que trate ex professo do problema do Comunismo.

A.1) No período preparatório do Concílio, quase 600 Padres o pediram, assim como também posteriormente durante as Sessões III e IV. O n. 19 é insuficiente, porque o ateísmo é um dos erros fundamentais do Comunismo, mesmo do "Comunismo não ateu" e deveria ser rechaçado por causa de sua negação de outras verdades fundamentais da Ordem natural (por ex. espiritualidade e imortalidade da alma, dignidade da pessoa humana, direito de propriedade, totalitarismo estatal etc.).

2) Os concílios têm que desmascarar os erros tal como na realidade vigoram em sua época, e não cabe dúvida de que a forma mais perniciosa, virulenta e militante do ateísmo de hoje é o Comunismo. Ter-se-ia, pois de tratar explicitamente dele neste Concílio, como o fez a Enc. "Divini Redemptoris" de Pio XI. Se isto não fosse feito, correr-se-ia o risco de crer que a Igreja retrocede e se desdiz por falsos temores, do que em condenação do Comunismo já foi dito em solenes documentos.

\footnotetext{
${ }^{13}$ A petição representava vários bispos de 86 países: "A América do Norte era representada na lista por dois países; a Oceania, por 4; a Europa, por 15; a Ásia, por 16; a América do Sul e Central, por 23 e a África, por 26. Vinte e quatro dos 86 países eram representados por 4 ou mais padres conciliares, isto é: Argentina, Austrália, Brasil, Chile, China-Formosa, Canadá, Guiné, Paraguai, Peru, Portugal, República da África do Sul, Espanha, Tanzânia, República Árabe Unida, Estados Unidos da América e Vietnam" (ARQUIVO DA CONGREGAÇÃO DO VERBO DIVINO DE ROMA, 1965).
} 
3) O Concílio Vaticano II tem um caráter eminentemente pastoral. Pois, talvez não haja hoje problema pastoral mais urgente que livrar os fiéis do contágio do ateísmo através do Comunismo, ao qual alguns creem que podem dar seu nome sem prejuízo de suas crenças religiosas. O Comunismo espera o silêncio da Igreja e conta com ele nesta oportunidade, como um elemento valiosíssimo para seu ulterior proselitismo e esforços de dominação universal.

4) O Concílio não pode frustrar as esperanças dos fiéis que esperam que não se silencie este perigo formidável do mundo, como também que não silencie outros gravíssimos problemas que os angustiam (a fome, a guerra...).

5) Milhares e milhares de católicos, ortodoxos, protestantes, judeus etc. que sofreram e sofrem ainda horrenda perseguição da parte do Comunismo, esperam deste Concílio que tanto se caracteriza por seus sentimentos ecumênicos, umas palavras de consolo e de solidariedade.

B.1) Não se diga que é inútil tratar do Comunismo no Concílio, uma vez que já o fizeram os últimos Romanos Pontífices. Ninguém poderá duvidar que seria uma enorme força se o Concílio abordasse o problema em concordância com os ensinamentos dos Papas, como sucede com outros problemas.

2) Outros temem que isto seria calamitoso para os cristãos que gemem sob o Comunismo, porém, será difícil que tais cristãos tenham de sofrer por isso mais do que sofrem já atrás das grades de ferro. Além disso: a) requerem-no precisamente os Padres que fizeram uma experiência da perseguição; b) da Igreja se espera a verdade.

C) não se pode deixar nada sem impressionar a consciência mundial, freando assim o ímpeto do Comunismo.

Os Padres abaixo assinados propõem à Secretaria Geral um modelo de texto que poderia ser incluído. Roma, 29 de setembro de 1965. Assinaturas... (ARQUIVO DA CÚRIA METROPOLITANA DE DIAMANTINA, 1965).

\section{Junto à petição encontrava-se a proposta do texto que reprovava o comunismo como}

a forma de ateísmo mais perigosa:

O comunismo nega a existência de Deus e de toda a ordem religiosa mormente a ordem sobrenatural; na lógica da necessidade, comprovada pela história, atinge também de muitos modos os próprios princípios fundamentais da ordem natural. Nega a espiritualidade e a imortalidade da alma humana; torce o verdadeiro sentido da liberdade, sobretudo em matéria religiosa, faz violência à genuína dignidade da pessoa, da família e da união conjugal, desconhece as normas estáveis e imutáveis da lei moral e da justiça; e por isso mesmo, considera justo e moral tudo o que contribui para a ditadura de seu partido [...]; ao admitir o direito à propriedade privada; tem como meio necessário de conseguir os bens terrenos, a luta entre as classes sociais; o Estado é concebido como totalitário e de tal modo que nenhum lugar digno é deixado aos indivíduos ou às sociedades intermediárias. Resulta daí que o comunismo deve ser repelido. Não só porque confessa o ateísmo, mas também por causa dos gravíssimos erros acima referidos e que a ele estão indissoluvelmente conexos, e pelo Magistério da Igreja já foi declarado como intrinsecamente perverso (cf. Encíclica Divino Redemptoris de Pio XI). A doutrina comunista deve ser considerada perniciosa também porque sobretudo em nossa época, em muitos lugares à prática comunista é acrescentado todo gênero de instrumentos de poder civil e político, e assim, com experimentados artifícios é propagada e imposta. Acontece, pois, serem desprezados pelo comunismo, os direitos de Deus e os direitos dos homens; a própria Igreja católica no exercício de sua missão não pode admitir tal prática e 
tal doutrina que a constrangem injustamente e a perseguem tristemente em seus membros (CONCÍLIO VATICANO 2, 1970, v.4, pt. 2, p. 716; AS IV/2, p. 716).

No briefing da Divine World Service, de 15 de outubro de 1965, Ralph M. Wiltgen traz em primeira mão a notícia do documento. Segundo ele, no mesmo espaço de tempo em que a petição seguia para os padres, Carli fez chegar a 800 padres uma declaração com dez motivos pelos quais o Concílio deveria pronunciar-se sobre o comunismo. Carli teria dito que "o Concílio quer ser eminentemente pastoral, mas qual argumento é de natureza mais pastoral que este?" (ARQUIVO DA CONGRAGAÇÃO DO VERBO DIVINO DE ROMA, 1965). Visando a demonstrar a necessidade de tal pronunciamento, o bispo afirma: "Os perseguidos do comunismo - católicos, ortodoxos, protestantes, hebreus, religiosos de qualquer religião - esperam o conforto, a solidariedade do Concílio" (CONGREGAÇÃO DO VERBO DIVINO DE ROMA, 1965). E termina:

\footnotetext{
Um eventual silêncio do Concílio, continuou o Bispo, depois do quanto disseram sobre o Comunismo, os últimos Papas e o Sto. Ofício, equivaleria a uma negação de quanto foi dito e feito até aqui; significaria minimizar o perigo e a gravidade intrínseca do comunismo. Daí viria um dano psicológico incalculável; além de que a Igreja teria tachada de oportunismo, de medo etc. (CONGREGAÇÃO DO VERBO DIVINO DE ROMA, 1965).
}

Em 13 de novembro, a comissão mista, responsável pelo esquema XIII, distribuiu-o novamente com algumas correções, porém, sem nenhuma referência ao comunismo. Na mesma congregação, Carli entregou à Presidência do Concílio, uma carta de protesto chamando a atenção para a proposta de emenda no prazo legal assinada por 450 padres. Como a comissão havia ignorado a petição, o Coetus tentou uma última cartada para que a matéria entrasse no texto final do esquema: só a partir de um placet iuxta modum poderiam ter a chance de modificar o texto. Assim sendo, chegou às mãos dos padres uma carta, datada de 13 de novembro, propondo que assinassem aquele modus. Não se pedia mais uma nova condenação do comunismo, mas que fosse "solenemente reafirmada pelo Concílio a doutrina que já há muito tempo era a da Igreja” (WILTGEN, 2007, p. 277).

Em 15 de novembro, a Divine World Service distribuiu comunicado afirmando que a petição com as 450 assinaturas não tinha sido levada em conta pela presidência do Concílio. O comunicado alertava para a gravidade do ocorrido e afirmava que 
[...] esta deliberada omissão da parte da Comissão, tornada evidente há dois dias (sábado) quando o texto foi distribuído, causou nos últimos dias uma imediata e intensa atividade daqueles Padres Conciliares que estavam convictos de que o Concílio cometerá um grave erro se não assumir uma atitude clara e direta sobre este problema (CONGREGAÇÃO DO VERBO DIVINO DE ROMA, 1965).

A partir do comunicado da Divine World News Service é possível presumir o clima do Concílio naqueles dias. Segundo o comunicado, a última tentativa para se fazer menção ao comunismo, ou seja, o modus preparado pelo Coetus no texto final do esquema tinha despendido grande energia ao distribuir em grande quantidade as propostas de emendas nas próprias residências dos padres conciliares, em Roma. Tal comunicado teve impacto na mídia geral, sendo publicado por vários jornais italianos.

Sobre a questão da negativa da presidência em torno da petição, o cardeal Eugenio Tisserant, decano do Conselho da Presidência, abriu um inquérito no qual se concluiu que teria havido uma grave violação dos procedimentos do Concílio. As conclusões da investigação foram levadas até Paulo VI. A batalha teria sido perdida, mas não por completa. O papa, refletindo a preocupação dos 450 padres, ordenou à Comissão Mista, em 24 de novembro, que incluísse uma nota de pé de página sobre os ensinamentos do Magistério sobre o comunismo. A Comissão cedeu e incluiu no esquema referências às encíclicas de Pio XI (Divini Redemptoris), Pio XII (Apostolorum Principis), João XXIII (Mater et Magistra) e Paulo VI (Ecclesiam Suam), que tratavam do comunismo. Sigaud teria comentado depois do ocorrido: "Ter o chapéu no bolso não é o mesmo de que tê-lo na cabeça" (WILTGEN, 2007, p. 280).

Em vista da não inserção, no esquema, de uma condenação clara do comunismo, o Coetus contactou novamente os bispos, em carta entregue a 800 padres em 3 de dezembro de 1965, afirmando:

[...] a comissão não quis fazer menção nem mesmo do nome do "comunismo", ou seja, o máximo perigo hodierno em matéria de pastoral; e também negligenciou a petição contida nos módulos alegando motivações insuficientes e levando com isso mais de 500 padres a votarem non placet ao Esquema XIII integral porque não seria mais possível obter emendas parciais (CAPRILE apud TURBANTI, 1997, p. 185).

Além disso, as seções que também se referiam ao matrimônio e à guerra ainda não eram satisfatórias para os conservadores. A votação final do esquema XIII, que se deu em 7 de dezembro de 1965, resultou assim em 7 votos nulos, 75 votos non placet e 2.309 votos placet.

Horizonte, Belo Horizonte, v. 9, n. 24, p. 1010-1029, dez. 2011 - ISSN: 2175-5841 


\section{Conclusão}

A atuação de Antônio de Castro Mayer e Geraldo de Proença Sigaud foi notória, especialmente deste último, no que tange às tentativas de impedir qualquer novidade na compreensão das relações da Igreja Católica e o mundo moderno. O Coetus Internationalis Patrum, grupo pelo qual agiram juntamente com outros bispos conservadores de todo o mundo, foi o canal no qual esses bispos atuaram e, a partir de manobras específicas dentro da assembleia conciliar, conseguiram, se não seus objetivos específicos, algumas vitórias pontuais. O estudo em torno da chamada "minoria conciliar" ainda dá seus primeiros $\operatorname{passos}^{14}$, já que até o momento, os historiadores se concentraram especialmente na atuação daqueles que marcaram o concílio em sua vertente de abertura. Todavia, apenas tornando nosso olhar também para a atuação desse grupo no concílio e, da mesma forma, o pósconcílio tradicionalista, poderemos compreender um pouco mais claramente a conjuntura da Igreja contemporânea nestes quase cinquenta anos de início do evento conciliar.

\section{REFERÊNCIAS}

ARQUIVO DA CONGREGAÇÃO DO VERBO DIVINO DE ROMA. Divine World News Service. Roma: [s.n.], 1965.

ARQUIVO DA CÚRIA METROPOLITANA DE DIAMANTINA. Fundo Arquivístico Geraldo de Proença Sigaud. Diamantina, 1965.

ARQUIVO DA CÚRIA METROPOLITANA DE DIAMANTINA. Fundo Arquivístico da Cúria Arquidiocesana de Diamantina. Geraldo de Proença Sigaud. Diamantina, [1963?].

ARQUIVO DA CÚRIA METROPOLITANA DE DIAMANTINA. Fundo do Istituto per le Scienze Religiose di Bologna. Florit. I/510. [1963?].

ARQUIVO DA BIBLIOTECA DOS REDENTORISTAS DE SÃO PAULO. Fundo Vaticano II. Dom Geraldo de Proença Sigaud. São Paulo, [1960?]

ARQUIVO DA BIBLIOTECA DOS REDENTORISTAS DE SÃO PAULO. Fundo

Vaticano II. Dom Geraldo de Proença Sigaud. São Paulo, 168.1/002, 1960.

${ }^{14}$ Cf., por exemplo, Buonasorte (2001; 2003; 2006); Lay (1993); Perrin (1991; 1995; 1997). 
ARQUIVO DA BIBLIOTECA DOS REDENTORISTAS DE SÃO PAULO. Fundo

Vaticano II. Dom Geraldo de Proença Sigaud. São Paulo, 168.1/012, 1963.

ARQUIVO DA BIBLIOTECA DOS REDENTORISTAS DE SÃO PAULO. Fundo

Vaticano II. Dom Geraldo de Proença Sigaud. São Paulo, 168.1/018, [1963?].

ARQUIVO DA BIBLIOTECA DOS REDENTORISTAS DE SÃO PAULO. Fundo

Vaticano II. Dom Geraldo de Proença Sigaud. São Paulo, 168.1/ [s.n], 1964.

BARAÚNA, Luiz J. Brasil. In: BEOZZO, José Oscar (Org.). A Igreja Latino-Americana às vésperas do Concílio: história do Concílio Ecumênico Vaticano II. São Paulo: Paulinas, 1993.

BEOZZO, José Oscar. A Igreja do Brasil no Concílio Vaticano II. São Paulo: Paulinas, 2005.

BUONASORTE, Nicla. Per la "pura, piena, integra fede cattolica": il p. Victor Alain Berto al concilio Vaticano II. Cristianesimo nella Storia, Bologna, n. 22, p. 111-151, 2001.

BUONASORTE, Nicla. Siri: tradizione e novecento. Bologna: Il Mulino, 2006.

BUONASORTE, Nicla. Tra Roma e Lefebvre: il tradizionalismo italiano nel Concilio Vaticano II. Roma: Edizioni Studium, 2003.

CALDEIRA, R. Coppe. Os baluartes da tradição: o conservadorismo católico brasileiro no Concílio Vaticano II. Curitiba: CRV, 2011.

CHALET, Jean-Anne. Monseigneur Lefebvre, o bispo rebelde. Rio de Janeiro: DIFEL, 1977.

CONCÍLIO VATICANO, 2, 1962-1965. Acta synodalia Sacrosancti Concilii

Oecumenici Vaticani II. Citá del Vaticano: Typis Polyglottis Vaticanis, 1970.

DENZINGER, Heinrich. Compêndio dos símbolos, definições e declarações de fé e moral. São Paulo: Paulinas, 2007.

FORACCHI, Marialice M. Mannheim. São Paulo: Ática, 1982.

KLOPPENBURG, Boaventura. Concílio Vaticano II: quarta sessão (1965). Petrópolis: Vozes, 1966. v. 5.

KLOPPENBURG, Boaventura. Concílio Vaticano II: segunda sessão (1963). Petrópolis: Vozes, 1963. v.3.

LAY, Benny. Il papa non eletto: Giuseppe Siri cardinale di Santa Romana Chiesa. RomaBari: Laterza, 1993.

MOTTA, Rodrigo Patto Sá. Em guarda contra o perigo vermelho. São Paulo: Perspectiva, 2002. 
PERRIN, Luc. Il caso Lefebvre. Genova: Marietti, 1991.

PERRIN, Luc. Il Coetus Internationalis Patrum e la minoranza conciliare. In: FATTORI, M. T.; MELLONI, A. (a cura di). L'evento e le decisioni: studi sulle dinamiche del Concilio Vaticano II. Bologna: Il Mulino, 1997.

PERRIN, Luc. L' “eresia” dell'aggiornamento. Paura e negazione di uma alterità dentro la Chiesa dopo il Vaticano II. In: MELLONI, A.; LA BELLA, G. (a cura di). L'alterità: concezione ed esperienze nel cristianesimo contemporaneo. Bologna: Il Mulino, 1995.

SIGAUD, Geraldo de Proença. Carta Pastoral de Saudação. São Paulo: [s.n.], 1947.

SIGAUD, Geraldo de Proença. Catecismo anticomunista. São Paulo: Vera Cruz, 1962.

TURBANTI, Giovanni. Il problema del comunismo al Concilio Vaticano II. In: MELLONI, Alberto (Dir.). Vatican II in Moscow (1959-1965). Leuven: Leuven Bibliotheek van de Faculteit Godgeleerdheid, 1997.

TURBANTI, Giovanni. Un concilio per il mondo moderno. La redazione della costituizione pastorale "Gaudium et spes" del Vaticano II. Bologna: Il Mulino, 2000.

WILTGEN, Ralph. O Reno se lança no Tibre: o concílio desconhecido. Niterói: Permanência, 2007. 